\title{
Prognostic Values of Stromal Proportion and PCNA, Ki-67, and p53 Proteins in Patients with Resected Adenocarcinoma of the Lung
}

Léa Maria Macruz Ferreira Demarchi, M.D., Márcia Martins Reis, M.S.,

Suely Aparecida Pinheiro Palomino, M.S., Cecília Farhat, Teresa Y. Takagaki, M.D., Ph.D.,

Ricardo Beyruti, M.D., Ph.D., Paulo Hilário Nascimento Saldiva, M.D., Ph.D.,

Vera Luiza Capelozzi, M.D., Ph.D.

Heart Institute (InCor) (LMMFD, MMR, SAPP), Department of Pathology (CF, PHNS, VLC), and

Pulmonary Division (TYT, RB), University of São Paulo Medical School, São Paulo, Brazil

Data from 64 patients who underwent surgical resection of lung adenocarcinomas were studied to identify clinicopathologic markers that might provide prognostic information on the clinical behavior of this neoplasia. Patient staging was performed in accordance with the tumor-node-metastasis system as follows: Stage I $(n=29)$, Stage II $(n=11)$, Stage IIIA $(n=21)$, and Stage IIIB $(n=3)$. Overall follow-up time corresponded to the follow-up time for patients who were alive and to the survival time for patients who had died, all of them expressed in months. Data included age, staging, histologic type, morphometric assessment of histologic features related to tumor (stroma and vascularization), and immunohistochemical detection of proliferation cell markers (Ki-67 protein and proliferating cell nuclear antigen) and p53 protein. The morphometric assessment was made by the point-counting procedure. Data analysis included Life Tables for Survival and Cox Regression models. Overall follow-up analysis showed that significant univariate predictors $(P<.05)$ were $T$ stage; $N$ stage; tumor stromal proportion; and immunohistochemical indexes of proliferating cell nuclear antigen, Ki-67, and p53 proteins. Variables that presented independent predictive value for overall follow-up with the multivariate model $(P<.05)$ were sex, $T$ stage, $N$ stage, tumor stromal proportion, and immunohistochemical detection of p53 protein. We conclude that tumor stromal proportion and immunohistochemical detection of p53 protein, controlled for sex, $\mathrm{T}$ stage,

Copyright () 2000 by The United States and Canadian Academy of Pathology, Inc.

VOL. 13, NO. 5, P. 511, 2000 Printed in the U.S.A.

Date of acceptance: October 26, 1999.

Address reprint requests to: Vera Luiza Capelozzi, M.D., Ph.D., Departamento de Patologia, Faculdade de Medicina da Universidade de São Paulo, Av. Dr. Arnaldo, 455 CEP 01246-903, São Paulo, SP Brazil; e-mail: vcapelozzi@lim05.fm.usp.br; fax: 5511-3064-2744. and $N$ stage, may be of critical value in the evaluation of recurrence of lung adenocarcinoma, serving as indicators for a more accurate prognosis.

KEY WORDS: Ki-67, Lung adenocarcinoma, Morphometry, p53, Prognosis, Proliferating cell nuclear antigen, Stroma.

Mod Pathol 2000;13(5):511-520

The aggressiveness of a tumor depends on the properties of neoplastic cells (cell proliferation, cell loss, angiogenesis, expression of oncogenes) and host response to tumor invasion (stromal framework). There is a good deal of evidence to suggest that the relationship between carcinomatous cells and the stromal framework influences the invasive and metastatic properties of the tumor cells themselves (1). The stromal framework can modulate the morphogenesis, differentiation, and mitogenesis of malignant tumors $(2,3)$. Conversely, it is also known that the proliferative activity of tumor cells can influence the growth of the stromal framework (4) and then account for their invasive and migratory properties (5). Variations in these aspects could therefore, at least partially, explain differences in invasive and metastatic properties among tumors of the same type.

In this respect, adenocarcinomas of the lung, displaying a wide spectrum of clinicopathologic features with varying prognosis (6), provide an interesting human tumor model to study the relationship between the stromal framework and the aggressiveness of the disease. In addition, surgical resection of adenocarcinoma is the only treatment that offers a prospect of long-term survival. Reliable methods of identifying prognostic markers of lung adenocarcinomas would improve the overall treatment of these patients. 
The proliferative activity of a tumor is a potentially useful indicator for predicting the prognosis of the disease (7). To evaluate changes related to tumor cell proliferation, we assessed the presence of proteins proliferating cell nuclear antigen (PCNA), Ki-67, and p53 in the neoplastic cells by immunohistochemical reaction, which is a simple and reasonably inexpensive method that could be performed at most laboratories.

In the present study, morphometric procedures were used to quantify histologic and immunohistochemical tumor markers of the aggressiveness of adenocarcinomatous cell (proportion of vascularization; histologic type; and immunohistochemical detection of PCNA, Ki-67, and p53 proteins) and host defense to invasion (tumor stromal proportion). Furthermore, the impact of these factors on overall follow-up was analyzed.

\section{PATIENTS AND METHODS}

Tumor specimens from 64 patients (43 men and 21 women) who had adenocarcinoma of the lung were assessed. All patients underwent surgical resection at Instituto do Coração and Hospital das Clínicas da Faculdade de Medicina de São Paulo between 1979 and 1994. The patients were selected on the basis of the tumor staging and the availability of paraffin blocks of the neoplasia. No chemotherapy or radiotherapy was administered before or after surgery. No patient had evidence of metastases to head, chest, abdomen, or bones at the time of surgery, according to computed tomographic scans and radionuclide scans. The mean patient age for this study was $59.8 \pm 11.1$ years (range, 33 to 84 years). All cases were staged after surgery using the International Staging System (8), and those with Stages I $(n=29)$, II $(n=11)$, IIIA $(n=21)$, and IIIB $(n=3)$ were enrolled in our study. Staging of each case was separated into tumor size (T stage) and nodal involvement ( $N$ stage) to evaluate the influence of these variables on overall follow-up. Information regarding patient age, sex, and follow-up data was obtained through medical records or from consultation with either the physician or the family of the patient. Overall follow-up time corresponded to the follow-up time for patients who were alive and to the survival time for patients who had died, all of them expressed in months. Follow-up time of a living patient was defined as the time from surgical intervention to the last information available about the patient's health. Survival time was defined as the time from surgical intervention to the date of the patient's death. Patients who died less than 1 month after operation and those whose follow-up was shorter than 12 months were not included in this study, except for one living patient who presented cancer recurrence after 8.1 months of follow-up. All overall follow-up figures were corrected for patients who were alive without $(n=20)$ and with cancer recurrence $(n=1)$ and for patients with non-cancer-related death $(n=2)$.

\section{MORPHOLOGIC EVALUATION}

Tumor tissue samples were obtained at surgical treatment of lung adenocarcinoma and fixed in $10 \%$ formalin. For each case, one or two slides of the principal tumor were selected by light microscopy. Acceptable sections were those that represented the predominant histologic subtype identified on the majority of slides, with at least 10 microscopic fields at a magnification of $\times 250$ representing adenocarcinoma, none or little necrosis, and minimal preparation artifact. Their respective paraffinembedded blocks were sectioned at $3 \mu \mathrm{m}$, mounted onto poly-L-lysine-coated slides, and stained with hematoxylin and eosin. Two pathologists reviewed these slides separately and in a randomized fashion and agreed on the diagnosis of lung adenocarcinoma. The histologic classification of each case was done in accordance with World Health Organization guidelines (9), based on the predominant histologic subtype identified on the majority of slides.

\section{MORPHOMETRIC EVALUATION}

The tumor proportions of stromal vascularization were determined by the point-counting technique (10), using a coherent system of 100 points and 50 lines attached to the eyepiece of a light microscope (Fig. 1). To fulfill the statistical requirements, the fields were sampled systematically and independent of their content-and of the observer-but all inside a well-defined region. The microscopic fields to evaluate proportion of morphologic parameters was determined mathematically to maintain the coefficient of variation or error of the procedure

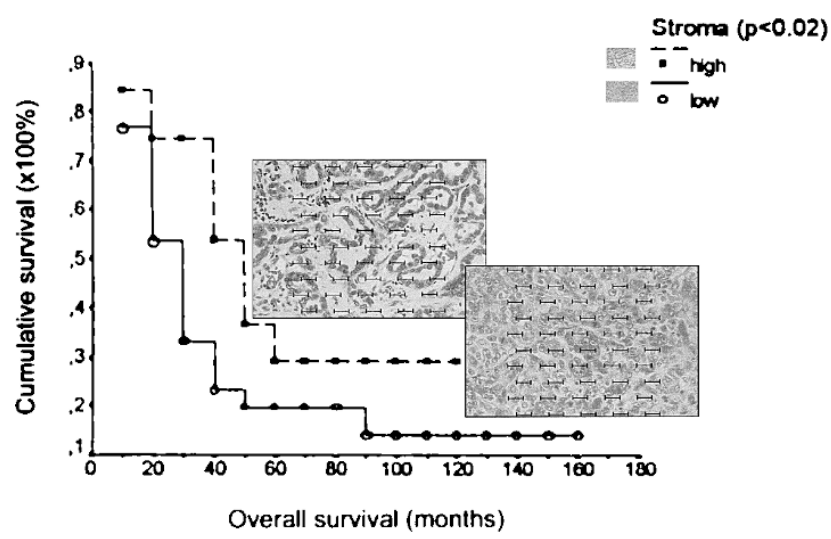

FIGURE 1. Illustration of the method for determining the amount of stroma and low stroma, high stroma, and related survival. 
always at less than $5 \%$ for 30,20 , or 10 microscopic fields. After this procedure, counting was performed using a cascade progressive sampling approach. The morphologic variables assessed for each patient were tumor stromal proportion (STRO) and tumor vascular proportion (VES). The stromal proportion was determined in 10 noncoincident microscopic fields in each case, at a magnification of $\times 250$, and was defined by the following relationship:

$$
\text { STRO }=\frac{\text { Pstro }}{\text { Ptu }}
$$

where Pstro is the average of the points overlying tumor stroma and Ptu is the average of the points overlying total tumor tissue.

The tumor vascular proportion was assessed in $3-\mu \mathrm{m}$ Verhoeff-stained sections, in 10 noncoincident microscopic fields in each case, at a magnification of $\times 400$, and was defined by this relationship:

$$
\text { VES }=\frac{(\text { Vintra }+ \text { Vperi })}{\text { Ptu }}
$$

where Vintra is the average of the points overlying vessels situated inside the tumor; Vperi is the average of the points overlying vessels situated in the boundary area between neoplastic/non-neoplastic lung tissue, each of them counted in 10 noncoincident fields; Ptu is the average of the points overlying total tumor tissue, at a magnification of $\times 400$.

\section{IMMUNOHISTOCHEMISTRY}

For each case, among the paraffin blocks used for morphologic and morphometric analysis, we selected the one that presented none or little necrosis. Histologic sections were cut at $3 \mu \mathrm{m}$ and mounted onto poly-L-lysine-coated slides. Immunohistochemical detection of PCNA, Ki-67, and p53 proteins was assessed. The immunohistochemical methods used have been proved to be accurate and reproducible by other authors (11-13).

\section{Tissue Preparation}

Paraffin sections were dewaxed in xylene and hydrated in graded ethanol. Antigen retrieval was done by heat treatment for p53 with $10 \mathrm{~min}$ of microwave, and for Ki-67 with 15 seconds in a pressure cooker. The slides were incubated overnight with the following primary antibodies: a monoclonal mouse antihuman p53 protein (DO7; Dako A/S, Glostrup, Denmark; dilution 1:40), a monoclonal mouse antibody nuclear antigen Ki-67 (MIB1; Immunotech, Marseille, France; dilution 1:400), and a monoclonal mouse anti-PCNA (PC 10; Dako A/S; dilution 1:80). Subsequent incubations with biotinylated rabbit antimouse immunoglobulins (Dako $\mathrm{A} / \mathrm{S}$ ) and a streptavidin-horseradish peroxidase conjugate (Amersham International plc, Buckinghamshire, England) were done. The reactions were developed with 3,3'-diaminobenzidine (Sigma Diagnostics, St. Louis, MO) and counterstained with Hematoxylin Solution Gill (Sigma Diagnostics). For positive controls, formalin-fixed paraffin sections of adenocarcinoma and squamous cell carcinoma of the lung known to be positive for PCNA, Ki-67, and p53 were stained simultaneously. For negative controls, sections were incubated with fetal bovine serum instead of the primary antibodies.

Immunohistochemical Indexes of PCNA, Ki-67, and p53 Proteins

Brownish nuclear staining was considered to be evidence of the antigen expression by cells, according to respective antibodies used. To determine the proliferation indexes after immunohistochemistry, we used conventional point counting (see Gendersen et al. 10), the same technique used for the morphometric evaluation (Fig. 1). At a magnification of $400 \times, 10$ noncoincident microscopic fields in each case were studied to quantify the amount of points overlying stained cells, counting a total of 1000 points that covered an area of $62,500 \mu \mathrm{m}^{2}$ / field/section, actually representing the proportion of stained positive cells in areas of tumoral tissue. The immunohistochemistry proliferation indexes were obtained by the following relationship:

$$
\mathrm{IPI}=\frac{\mathrm{Pih}}{\mathrm{Pt}}=(\% \text { section })
$$

where Pih and Pt are the numbers of points overlying tissue stained cells and tumor, respectively, expressed as a percentage.

For all morphometric procedures, an estimate of the error (CE) was computed by the following relationship:

$$
\mathrm{CE}=\frac{\mathrm{SE}}{\text { mean }}
$$

where SE represents the standard error of the mean. Considering the number of points counted, CE was kept under $10 \%$ in all morphometric measurements.

\section{STATISTICAL ANALYSIS}

The measured variable values of all cases were arranged in ascending order and divided into two groups on the basis of the median value of each 
variable. The groups were called low and high degree for each variable as follows: stromal proportion (low degree, $<24.30 \%$; high degree, $\geq 24.30 \%$ ), vascular proportion (low degree, $<7.55 \%$; high degree, $\geq 7.55 \%$ ), PCNA index (low degree, $<45.16 \%$; high degree, $\geq 45.16 \%$ ), Ki-67 index (low degree, $<22.22 \%$; high degree, $\geq 22.22 \%$ ), and p53 index (low degree, $<6.45 \%$; high degree, $\geq 6.45 \%$ ). Overall survival analysis was done in two steps. In the first test, we performed univariate analysis relating overall follow-up time to each of the measured variables by means of Life Tables of Survival (14). Briefly, the basic idea of the life table is to subdivide the period of observation after a starting point, such as surgical resection for lung cancer, into smaller time intervals, say, single months. For each interval, all people who have been observed at least that long are used to calculate the probability that an event, such as death, will occur in that interval. The probabilities estimated from each of the intervals are then used to estimate the overall probability of the event's occurring at different time points. All available data are used for the computations. This series of analysis was used to select the variables that exhibited a significant association with overall follow-up $(P<.05)$. The significant variables selected on the basis of a univariate model were considered in the multivariate analysis of the Cox Regression test (14), using different model specifications. The patient's sex was also considered in the multivariate analysis, because it presented a marginal statistical value $(P<.08)$ in the univariate model, very near the statistical value considered as significant $(P<.05)$. We defined as a positive event any death caused by cancer recurrence. Deaths from causes other than lung cancer $(n=2)$ and living patients $(n=21)$ were considered in the models as censored cases. All statistical procedures were performed with SPSS version 6.0 statistical software (SPSS, Inc., Chicago, IL).

\section{RESULTS}

Table 1 shows clinical, histologic, morphometric, immunohistochemical, and survival data of the patients. The population included 21 women $(32.8 \%)$ and 43 men $(67.2 \%)$. The mean follow-up time of the living patients was $51.9 \pm 41.27$ months (range, 8.1 to 164.9 months). Mean survival time was $23.6 \pm$ 20.54 months (range, 1.7 to 135.5 months). At the end of the study, 41 patients had died of lung cancer, 2 patients had died of other causes without evidence of lung adenocarcinoma, 20 patients were alive without cancer recurrence, and 1 patient was alive with recurrent cancer. The recurrence rate of cancer was $65.6 \%$ (42 of 64 patients).

In the first statistical test, the individual effect of patient characteristics (age, sex, T stage, $N$ stage), primary tumor variables (histologic type, proportions of stroma, and vascularization), and indexes of proliferation markers (PCNA and Ki-67 proteins) and p53 protein were examined to estimate statistical differences using Life Tables of Survival (Table 2). As expected, the results of this analysis showed that the prognosis of patients who had adenocarcinoma of the lung is dependent on the T and $N$ stages of the disease $(P<.007$ and $P<.03$, respectively). Sex presented a marginal significant value $(P<.08)$, and male sex seemed to have an increased overall cancer recurrence than female (Fig. 2A). As observed in Figure 2B, tumor size (T stage) larger than $3 \mathrm{~cm}$, as in T3 and T4 disease, was a significant predictor $(P<.007)$ of invasion by lung tumors of adjacent structures (chest wall, mediastinum). The presence of nodal involvement was also significantly associated with cancer recurrence $(P<.03)$. A significant increase in overall survival time was observed for tumors with high proportion of stroma $(P<.02$; Fig. 2C). Figure 1 illustrates the method for determining the amount of stroma and low stroma, high stroma, and related survival. The curve analysis stratified by stroma proportion shows that 10 months after surgical resection, $10 \%$ of the patients who had high stromal proportion in tumors will be dead. For the same interval, approximately $25 \%$ of the patients will be dead if their tumors exhibit a low proportion of stroma. Similarly, death caused by cancer was significantly associated with high proliferation indexes of PCNA $(P<.007)$ and Ki-67 $(P<.01$; Figs. 2D and E, respectively) and a high index of p53 protein $(P<$ .05; Fig. 2F). Morphologic variables related to tumor aggressiveness, such as histologic subtypes and proportion of vascularization, were not significant predictors of recurrence of lung adenocarcinoma.

Multivariate analysis of overall survival time based on significant and marginal significant factors at univariate analysis was examined by the Cox Regression model. Initially, the model was constructed with patient sex, tumor size, and nodal involvement (Table 3). In this situation, tumor size and nodal involvement were maintained as independent prognostic factors; sex did not show a significant statistical value $(P<.12)$. Thus, proportion of stroma was introduced into the model, controlled for sex, tumor size, and nodal involvement (Table 4). This new situation showed that tumor size, nodal involvement, and stroma were significantly related to overall survival, but sex did not show statistical value as a predictor of cancer recurrence. A third model, which excluded stroma and introduced indexes of PCNA, Ki-67, and p53 proteins, controlled for tumor size, nodal involvement, and sex. As shown in Table 5, among the three immunohistochemical markers, only p53 was significant in predicting cancer recurrence. Finally, 
TABLE 1. Clinical, Histologic, Morphometric, and Immunohistochemical Data

\begin{tabular}{|c|c|c|c|c|c|c|c|c|c|c|c|}
\hline Patients & Age & Sex & Stage $(\mathrm{TN})$ & Histologic Type & $\begin{array}{l}\text { Survival } \\
\text { (mo) }\end{array}$ & $\begin{array}{l}\text { Follow- } \\
\text { Up (mo) }\end{array}$ & $\begin{array}{c}\text { Stroma } \\
(\%)\end{array}$ & $\begin{array}{c}\text { Vessels } \\
(\%)\end{array}$ & $\begin{array}{c}\text { PCNA } \\
(\%)\end{array}$ & $\begin{array}{c}\text { Ki-67 } \\
(\%)\end{array}$ & $\begin{array}{l}\text { p53 } \\
(\%)\end{array}$ \\
\hline 1 & 72 & $\mathrm{~F}$ & I (T2N0) & Acinar & & 17.7 & 38.0 & 3.9 & 23.2 & 0.0 & 49.7 \\
\hline 2 & 53 & $\mathrm{M}$ & I (T2N0) & Papillary & 32.1 & & 32.3 & 3.2 & 27.6 & 0.0 & 50.9 \\
\hline 3 & 60 & M & IIIA (T3N1) & Bronchioloalveolar & & 29.6 & 26.4 & 12.7 & 47.3 & 0.0 & 0.0 \\
\hline 4 & 33 & $\mathrm{M}$ & I (T2N0) & Bronchioloalveolar & 3.6 & & 12.1 & 16.4 & 58.0 & 5.0 & 0.0 \\
\hline 5 & 59 & M & I (T2N0) & Acinar & 10.1 & & 12.1 & 8.6 & 61.7 & 32.6 & 59.3 \\
\hline 6 & 41 & $\mathrm{~F}$ & II (T1N1) & Bronchioloalveolar & 14.9 & & 22.1 & 4.9 & 43.3 & 7.3 & 60.7 \\
\hline 7 & 68 & M & IIIB (T4N0) & Bronchioloalveolar & 36.9 & & 26.6 & 10.9 & 29.1 & 0.0 & 0.0 \\
\hline 8 & 35 & $\mathrm{~F}$ & I (T2N0) & Solid & & 164.9 & 19.1 & 15.0 & 14.8 & 10.8 & 0.0 \\
\hline 9 & 54 & M & IIIA (T3N0) & Solid & 1.7 & & 9.5 & 32.5 & 63.8 & 33.3 & 62.6 \\
\hline 10 & 54 & $\mathrm{~F}$ & IIIA (T3N1) & Acinar & 6.9 & & 25.0 & 11.3 & 52.4 & 37.0 & 5.4 \\
\hline 11 & 60 & $\mathrm{M}$ & IIIA (T2N2) & Acinar & 3.8 & & 47.3 & 8.0 & 47.6 & 48.7 & 0.0 \\
\hline 12 & 53 & M & IIIA (T2N2) & Solid & 3.1 & & 35.9 & 14.4 & 60.9 & 32.6 & 52.2 \\
\hline 13 & 48 & $\mathrm{~F}$ & I (T2N0) & Acinar & 43.9 & & 24.3 & 9.5 & 22.2 & 16.2 & 24.3 \\
\hline 14 & 60 & $\mathrm{~F}$ & IIIA (T1N2) & Bronchioloalveolar & 26.8 & & 14.6 & 4.8 & 33.7 & 10.7 & 11.0 \\
\hline 15 & 61 & M & IIIA (T2N2) & Acinar & 28.3 & & 22.4 & 7.9 & 52.7 & 35.1 & 6.1 \\
\hline 16 & 60 & M & IIIA (T3N2) & Bronchioloalveolar & 5.7 & & 13.6 & 17.0 & 51.7 & 40.6 & 0.0 \\
\hline 17 & 60 & $\mathrm{~F}$ & IIIA (T3N1) & Acinar & 54.6 & & 32.5 & 2.6 & 61.6 & 21.6 & 8.8 \\
\hline 18 & 68 & $\mathrm{M}$ & I (T1N0) & Acinar & 22.8 & & 9.9 & 7.5 & 66.9 & 37.0 & 0.0 \\
\hline 19 & 55 & M & IIIB (T4N0) & Acinar & 40.7 & & 28.1 & 4.6 & 20.1 & 17.2 & 0.0 \\
\hline 20 & 50 & M & I (T2N0) & Papillary & 23.1 & & 20.8 & 11.4 & 16.3 & 0.0 & 0.0 \\
\hline 21 & 62 & M & II (T2N1) & Papillary & 13.5 & & 14.2 & 5.9 & 29.5 & 0.0 & 0.0 \\
\hline 22 & 55 & M & IIIA (T3N0) & Acinar & 33.7 & & 5.7 & 18.0 & 32.7 & 13.7 & 0.0 \\
\hline 23 & 68 & M & I (T2N0) & Acinar & 11.7 & & 43.7 & 6.2 & 55.0 & 18.9 & 0.0 \\
\hline 24 & 53 & $\mathrm{~F}$ & IIIA (T2N2) & Bronchioloalveolar & 32.5 & & 26.0 & 6.9 & 8.9 & 0.0 & 0.0 \\
\hline 25 & 66 & M & I (T2N0) & Acinar & & 99.9 & 35.8 & 16.8 & 46.2 & 34.6 & 0.0 \\
\hline 26 & 60 & $\mathrm{~F}$ & IIIA (T2N2) & Acinar & 38.9 & & 41.5 & 7.4 & 67.4 & 0.0 & 65.4 \\
\hline 27 & 72 & M & I (T2N0) & Bronchioloalveolar & 81.4 & & 23.9 & 11.3 & 61.3 & 25.0 & 0.0 \\
\hline 28 & 70 & $\mathrm{~F}$ & II (T2N1) & Acinar & & 127.3 & 35.3 & 12.3 & 19.6 & 5.1 & 6.8 \\
\hline 29 & 59 & M & I (T1N0) & Bronchioloalveolar & 44.6 & & 18.5 & 6.8 & 0.0 & 11.9 & 29.4 \\
\hline $30^{a}$ & 82 & M & I (T2N0) & Acinar & 99.5 & & 33.5 & 4.5 & 38.6 & 0.0 & 3.9 \\
\hline 31 & 74 & $\mathrm{~F}$ & I (T1N0) & Acinar & 22.5 & & 14.4 & 11.6 & 32.0 & 26.3 & 35.0 \\
\hline 32 & 57 & M & II (T2N1) & Solid & 36.8 & & 17.8 & 6.4 & 44.1 & 22.9 & 0.0 \\
\hline 33 & 68 & M & II (T2N1) & Solid & 10.5 & & 7.7 & 12.0 & 58.6 & 23.1 & 67.0 \\
\hline 34 & 67 & $\mathrm{M}$ & IIIA (T3N2) & Papillary & 8.7 & & 29.9 & 18.5 & 68.9 & 39.4 & 45.2 \\
\hline $35^{a}$ & 64 & $\mathrm{M}$ & II (T2N1) & Solid & 6.5 & & 37.3 & 3.4 & 18.1 & 34.9 & 13.6 \\
\hline 36 & 54 & $\mathrm{M}$ & I (T2N0) & Acinar & 17.9 & & 36.6 & 6.9 & 38.7 & 7.2 & 30.7 \\
\hline 37 & 55 & $\mathrm{~F}$ & I (T2N0) & Acinar & & 97.9 & 16.6 & 7.6 & 14.6 & 0.0 & 0.0 \\
\hline 38 & 76 & M & I (T2N0) & Acinar & & 58.7 & 25.6 & 9.8 & 53.4 & 14.2 & 0.0 \\
\hline 39 & 50 & $\mathrm{~F}$ & II (T2N1) & Papillary & & 45.3 & 23.3 & 7.1 & 41.7 & 0.0 & 0.0 \\
\hline 40 & 50 & M & I (T2N0) & Solid & & 88.6 & 16.0 & 7.2 & 75.5 & 52.0 & 0.0 \\
\hline 41 & 62 & $\mathrm{~F}$ & I (T2N0) & Acinar & & 54.7 & 20.8 & 2.4 & 72.1 & 29.8 & 66.4 \\
\hline 42 & 80 & $\mathrm{~F}$ & IIIA (T3N0) & Solid & 8.8 & & 14.6 & 7.0 & 77.3 & 43.0 & 39.6 \\
\hline 43 & 52 & M & I (T2N0) & Solid & 17.0 & & 10.2 & 9.1 & 68.5 & 36.3 & 0.0 \\
\hline 44 & 73 & M & I (T2N0) & Acinar & 33.6 & & 13.7 & 7.9 & 69.0 & 30.1 & 63.0 \\
\hline 45 & 58 & M & I (T1N0) & Acinar & & 16.6 & 43.9 & 11.3 & 10.8 & 28.9 & 55.2 \\
\hline 46 & 67 & $\mathrm{~F}$ & I (T2N0) & Papillary & & 33.8 & 28.4 & 16.0 & 39.8 & 19.7 & 0.0 \\
\hline 47 & 43 & $\mathrm{~F}$ & IIIA (T3N0) & Solid & 12.5 & & 14.2 & 2.1 & 79.3 & 24.0 & 88.8 \\
\hline 48 & 62 & M & IIIA (T3N2) & Acinar & 9.8 & & 14.2 & 11.5 & 64.7 & 33.3 & 39.2 \\
\hline 49 & 65 & $\mathrm{M}$ & II (T2N1) & Papillary & & 29.2 & 41.8 & 4.7 & 48.7 & 48.4 & 61.3 \\
\hline 50 & 57 & M & IIIA (T3N0) & Acinar & & 24.0 & 26.3 & 6.6 & 81.5 & 48.8 & 0.0 \\
\hline 51 & 79 & M & IIIA (T3N2) & Papillary & 3.1 & & 15.9 & 7.7 & 51.2 & 47.6 & 45.1 \\
\hline 52 & 63 & $\mathrm{~F}$ & I (T1N0) & Acinar & & 26.2 & 38.4 & 8.3 & 79.0 & 27.6 & 0.0 \\
\hline 53 & 51 & M & II (T2N1) & Acinar & & 27.0 & 29.4 & 3.6 & 24.5 & 17.7 & 34.5 \\
\hline 54 & 44 & M & IIIA (T2N2) & Bronchioloalveolar & & 22.6 & 30.7 & 7.3 & 18.7 & 23.1 & 4.3 \\
\hline 55 & 52 & M & IIIA (T2N2) & Acinar & 9.5 & & 16.7 & 5.5 & 16.2 & 22.8 & 0.0 \\
\hline 56 & 84 & M & I (T2N0) & Acinar & 10.6 & & 22.6 & 4.1 & 0.0 & 0.0 & 39.8 \\
\hline 57 & 45 & M & II (T2N1) & Solid & & 49.8 & 37.5 & 4.9 & 54.8 & 40.0 & 2.8 \\
\hline 58 & 75 & M & I (T2N0) & Bronchioloalveolar & & 18.0 & 26.6 & 19.1 & 27.5 & 17.7 & 0.0 \\
\hline 59 & 54 & M & III (T3N1) & Acinar & 7.1 & & 36.2 & 4.4 & 69.2 & 13.5 & 58.8 \\
\hline $60^{b}$ & 72 & $\mathrm{~F}$ & II (T2N1) & Papillary & & 8.1 & 13.9 & 11.8 & 27.6 & 10.9 & 7.8 \\
\hline 61 & 65 & $\mathrm{~F}$ & IIIB (T1N3) & Bronchioloalveolar & 43.0 & & 33.6 & 15.4 & 0.0 & 0.0 & 45.5 \\
\hline 62 & 36 & $\mathrm{~F}$ & I (T2N0) & Acinar & 24.1 & & 9.8 & 4.7 & 32.4 & 67.0 & 46.7 \\
\hline 63 & 65 & $\mathrm{M}$ & I (T1N0) & Bronchioloalveolar & & 50.4 & 34.8 & 7.0 & 11.1 & 0.0 & 2.6 \\
\hline 64 & 59 & M & I (T2N0) & Acinar & 18.4 & & 24.3 & 5.1 & 54.5 & 34.3 & 55.9 \\
\hline
\end{tabular}

PCNA, proliferating cell nuclear antigen.

${ }^{a}$ Death caused by causes other than lung adenocarcinoma.

${ }^{b}$ Alive with lung cancer recurrence. 
TABLE 2. Coefficients of Univariate Analysis by Life Tables of Survival Relating Overall Follow-Up Time to the Variables of the Study

\begin{tabular}{|c|c|c|}
\hline Variables & Subset $(n)$ & $P$ value \\
\hline Age (y) & $\begin{array}{l}\leq 60(36) \\
>60(28)\end{array}$ & 0.35 \\
\hline Sex & $\begin{array}{r}\text { Female (21) } \\
\text { Male (43) }\end{array}$ & 0.08 \\
\hline T stage & $\begin{array}{l}\mathrm{T} 1+\mathrm{T} 2(49) \\
\mathrm{T} 3+\mathrm{T} 4(15)\end{array}$ & 0.007 \\
\hline $\mathrm{N}$ stage & $\begin{array}{l}\text { N0 (36) } \\
\text { N1 (15) } \\
\text { N2 (12) } \\
\text { N3 (1) }\end{array}$ & 0.03 \\
\hline Histologic type & $\begin{array}{c}\text { Bronchioloalveolar (13) } \\
\text { Acinar (31) } \\
\text { Papillary (9) } \\
\text { Solid (11) }\end{array}$ & 0.65 \\
\hline Stroma proportion (\%) & $\begin{array}{l}<24.30 \\
\geq 24.30\end{array}$ & 0.02 \\
\hline Vascularization proportion (\%) & $\begin{array}{l}<7.55(32) \\
\geq 7.55(32)\end{array}$ & 0.26 \\
\hline PCNA index (\%) & $\begin{array}{l}<45.16(32) \\
\geq 45.16(32)\end{array}$ & 0.007 \\
\hline Ki-67 index (\%) & $\begin{array}{l}<22.22(32) \\
\geq 22.22(32)\end{array}$ & 0.01 \\
\hline p53 index (\%) & $\begin{array}{l}<6.45(32) \\
\geq 6.45(32)\end{array}$ & 0.05 \\
\hline
\end{tabular}

PCNA, proliferating cell nuclear antigen.

stroma was introduced again in the model to verify the joint effects of variables that had already presented significant or marginal statistical values in the univariate analysis (Table 6). In this new situation, sex, tumor size, nodal involvement, stromal proportion, and p53 index exhibited a significant association with cancer recurrence. Thus, male patients, tumor measuring more than $3 \mathrm{~cm}$, neoplastic involvement of lymph nodes, low proportion of stroma, and high index of p53 protein are associated with cancer recurrence.

\section{DISCUSSION}

Among several types of lung carcinoma, a gradual increase in the incidence of adenocarcinoma has been recognized (15). However, the pathologic and biologic behavior of lung adenocarcinoma is not fully characterized, and the outcome of surgical treatment remains unsatisfactory, because approximately $35 \%$ of patients who have Stage I adenocarcinoma die as a result of spread of cancer within 5 years after resection (16). Although the tumornode-metastasis system is the simplest and best method for assessing the prognosis, several authors have studied other prognostic indicators for pulmonary adenocarcinoma, such as histologic differentiation (17), vascular invasion $(17,18)$, detection of oncoproteins (19-21) and proliferation markers $(11,22,23)$, and DNA ploidy $(20,24)$.

Among the histopathologic features, stromal proliferation may be marked in adenocarcinomas and is one of the most important prognostic factors already demonstrated (25). Although several studies of stromal proliferation in lung cancer have been conducted $(26,27)$, association with histopathologic, proliferative, and oncogenic characteristics, as well as the impact of these factors on overall survival, has not previously been considered.

In the current study, the analysis of Table 3 and Figure 2C indicates that the morphometric variable describing stromal proportion was of prognostic significance, and it may provide useful information on prognosis for patients who have adenocarcinoma and thus could influence clinical decisions or different therapeutic approaches. The results showed that tumors with a high proportion of stroma had a better outcome than those with a low proportion (Figs. 1 and 2C). Stromal proliferation is an important, though poorly understood, collagenous host response to tumor invasion (28). Growth factors (29), extracellular matrix enzymes (30, 31), and proliferative activity of tumor cells (4) form an intricate network of cooperative factors that regulate stromal proliferation. One of the first studies of the impact of stromal proliferation on the prognosis of lung adenocarcinoma was reported by Shimosato et al. in 1980 (25). Analysis of the cases revealed that in adenocarcinomas with desmoplasia, the degree of pleural invasion and the incidence of lymph node metastasis and blood vessel invasion were greater; thus, the prognosis was poorer than in cases with no or light desmoplasia. In a subsequent study, Madri and Carter (32) did not find differences between the degree of desmoplasia and stage of tumor or the survival rate, and they inferred that stromal proliferation most likely represents a host response to the tumor. However, in these studies, multivariate analysis of complete pathologic descriptions, morphometry, and other major prognostic factors in adenocarcinomas was not analyzed. Takise et al. (33) studied 75 adenocarcinomas and failed to show a statistically significant correlation of desmoplasia with overall survival by multivariate analysis. Although in a univariate analysis desmoplasia was found to be a significant predictor of relapse, the wide range of stages included in this study limits the value of any conclusion.

In contrast to previous works that were based on subjective or semiquantitative assessment of stroma, our study utilizes stereologic estimates, which are a more objective method of quantifying histopathologic characteristics $(34,35)$. The study included Stages I to III, and none of the patients received treatment other than surgery. Bias from preoperative mortality was eliminated, and the endpoint of analysis was overall survival. Patient age and sex as well as other known prognostic markers (histologic subtypes; vascularization and stromal proportions; and PCNA, Ki-67, and p53 indexes) were also taken into account in the univar- 
A

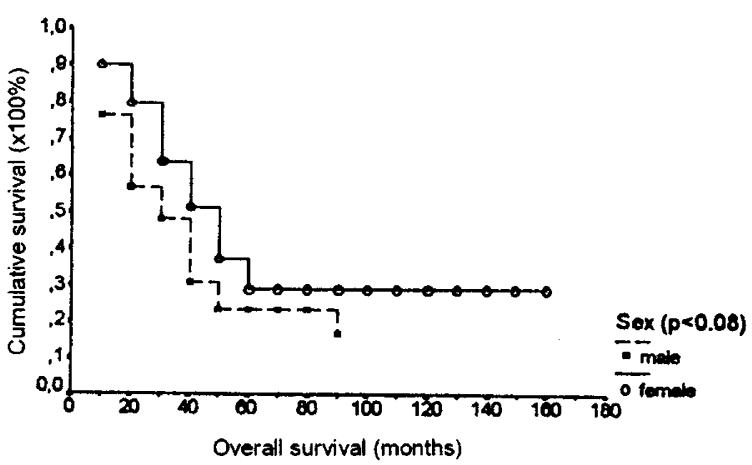

C

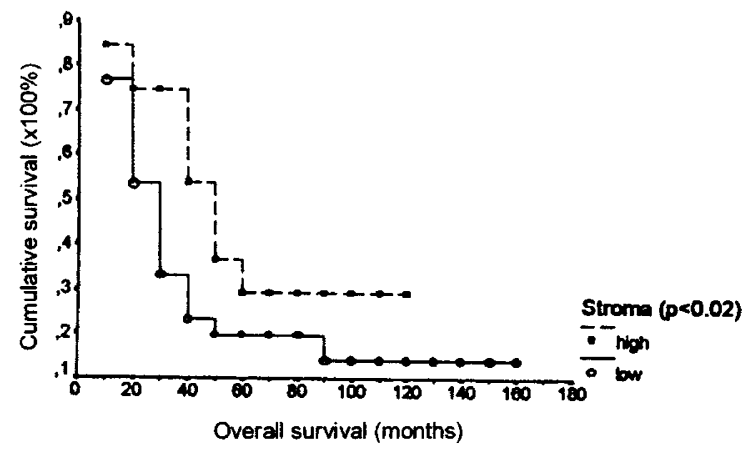

$\mathbf{E}$

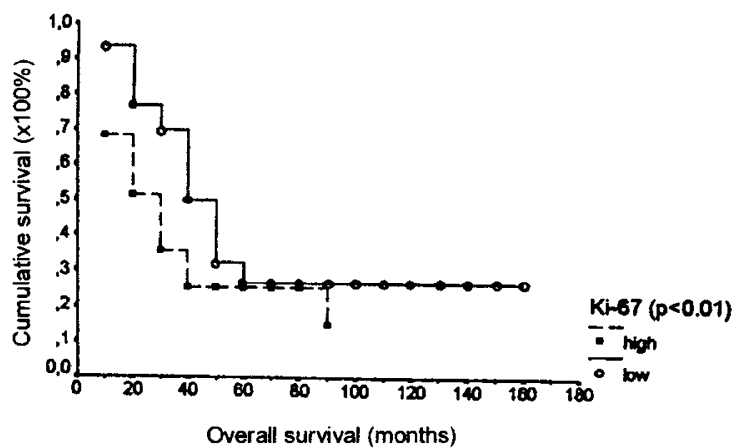

B

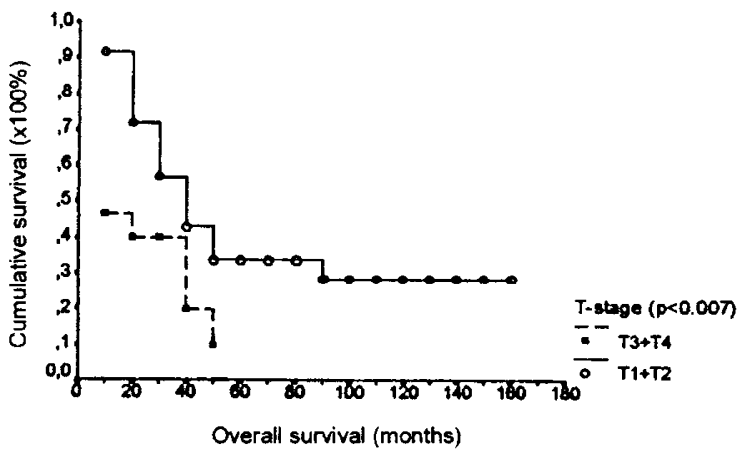

D

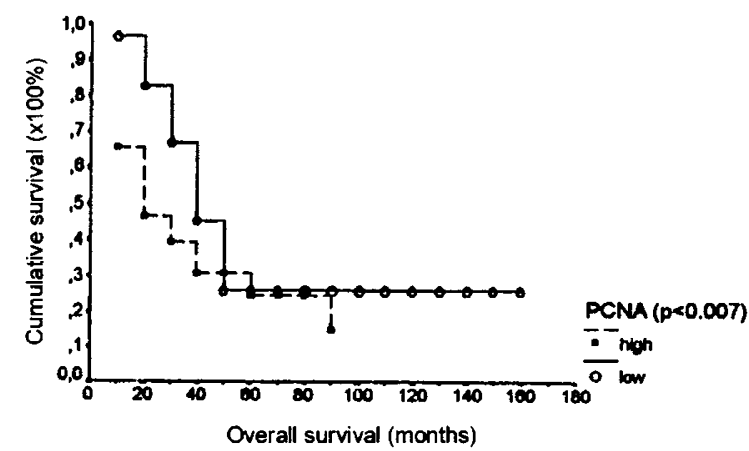

F

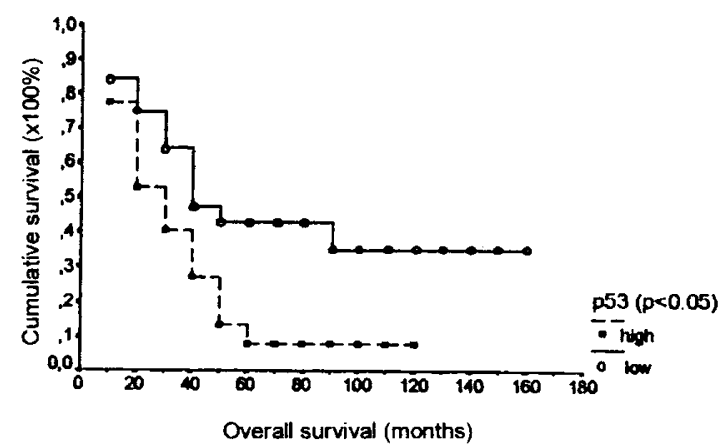

FIGURE 2. Overall survival curves of patients stratified by sex (A), T stage (B), stroma proportion (C), proliferating cell nuclear antigen (PCNA) proliferation index (D), Ki-67 proliferation index (E), and p53 protein index (F), using life tables of survival.

TABLE 3. Coefficients Attributed by Cox Multivariate Analysis Relating Sex, T Stage, and N Stage to Overall Survival

\begin{tabular}{lccc}
\hline Variables & $\beta$-Coefficient & Standard Error of $\beta$ & Significance \\
\hline Sex & -0.2894 & 0.1889 & 0.12 \\
T Stage & -0.5083 & 0.1791 & 0.004 \\
N Stage & -0.5519 & 0.3476 & 0.002 \\
\hline
\end{tabular}

iate and multivariate analyses. A univariate analysis of overall survival showed that stromal proportion was the only histologic factor that acquired a significant statistical value, whereas proliferative indexes (PCNA and Ki-67) and index of p53 evaluated by immunohistochemical detection showed significant association with cancer recurrence. Tumor size and nodal involvement were significant as in-
TABLE 4. Coefficients Attributed by the Cox Multivariate Analysis for Stroma Proportion Controlled for Sex, $T$ stage, and $N$ stage

\begin{tabular}{lccc}
\hline Variables & $\beta$-Coefficient & Standard Error of $\beta$ & Significance \\
\hline Sex & -0.5872 & 0.3720 & 0.11 \\
T stage & -1.1756 & 0.3663 & 0.001 \\
N stage & -1.2971 & 1.0968 & 0.003 \\
Stroma & 0.9092 & 0.3445 & 0.008 \\
\hline
\end{tabular}

dividual predictors of overall cancer survival $(P<$ .007 and $P<.03$, respectively). The impact on tumors measuring more than $3 \mathrm{~cm}$ (T2) and neoplastic nodal involvement on survival in adenocarcinoma is the most consistent finding in the literature $(16,36)$ and was also confirmed by our study. Also in our study, tumor size, as in T3 and T4 disease, 
TABLE 5. Coefficients Attributed by the Cox Multivariate Analysis for PCNA, Ki-67, and p53 Indexes Controlled for Sex, T Stage, and N Stage

\begin{tabular}{lccc}
\hline Variables & $\beta$-Coefficient & Standard Error of $\beta$ & Significance \\
\hline Sex & -0.8827 & 0.4236 & 0.03 \\
T stage & -1.1755 & 0.3899 & 0.003 \\
N stage & -0.4204 & 1.0807 & 0.01 \\
PCNA & 0.2597 & 0.4415 & 0.55 \\
Ki-67 & -0.7134 & 0.4642 & 0.12 \\
p53 & -1.2090 & 0.3741 & 0.001 \\
\hline
\end{tabular}

PCNA, proliferating cell nuclear antigen.

TABLE 6. Coefficients Attributed by the Cox Multivariate Analysis for Stroma Proportion, PCNA, Ki67, and p53 Indexes Controlled for Sex, T Stage, and N Stage

\begin{tabular}{lccc}
\hline Variables & $\beta$-Coefficient & Standard Error of $\beta$ & Significance \\
\hline Sex & -0.9671 & 0.4145 & 0.01 \\
T stage & -1.2193 & 0.3965 & 0.002 \\
N Stage & -0.8993 & 1.1090 & 0.01 \\
Stroma & 0.7878 & 0.3729 & 0.03 \\
PCNA & 0.1306 & 0.4705 & 0.78 \\
Ki-67 & -0.3906 & 0.5073 & 0.44 \\
p53 & -1.1517 & 0.3678 & 0.002 \\
\hline
\end{tabular}

PCNA, proliferating cell nuclear antigen.

was a significant predictor of invasion by lung tumors of adjacent structures (chest wall, mediastinum). Evaluation of histologic subtyping of adenocarcinoma revealed no association with overall survival despite reports of previous studies (37), probably because of interobserver and intraobserver variability concerning the histologic subtype (6). This source of uncertainty probably contributed to the placement of pathologic information in a secondary position to clinical studies, which usually make little use of pathologic reports on the histologic subtypes. To verify whether pathologists could contribute more efficiently to the establishment of clinical outcome, our group has used quantitative techniques on routine processed material of lung cancer showing that simple stereologic estimators are useful for predicting prognosis in patients who have lung cancer (35). In this context, among the estimated quantitative histopathologic variables, we found prognostic value of the stromal proportion even when clinical data were included in the model (Table 5). Studies of adenocarcinomas of the lung and other organs have shown a significant association between stromal proliferation and prognosis (26-30). However, in contrast to previous reports in the literature $(34,38)$, in our series, vascularization was not significant as a survival predictor, probably because we should approach tumor vascularization by other methods rather than histochemical staining. In this context, adenocarcinoma of the lung indicates that additional measurements of pathologic characteristics should be taken and combined with biologic factors to verify whether it is possible to increase the efficiency of survival prediction for patients who undergo surgical resection for limited adenocarcinoma of the lung. Evaluation of overall survival in the current study demonstrated that nodal involvement and stromal proportion were significant predictors of overall survival. Therefore, they must be useful in evaluating survival of patients who have lung adenocarcinoma.

The evaluation of the tumor cell proliferative characteristics is a potentially useful indicator for predicting the prognosis of the disease (7). PCNA (22) and Ki-67 $(11,23)$ proteins are routine markers of cell proliferation. p53 protein is a product of p53 tumor suppressor gene, which is known to play an important role in the control of cell proliferation and carcinogenesis (19-22).

PCNA is a 261 amino acid protein known as an auxiliary protein of DNA polymerases, the synthesis of which has been reported to be directly correlated to DNA replication and cell proliferation (22). In the cell cycle, the PCNA expression increases late in the $G_{1}$ phase, reaches its maximum in the $S$ phase, and then declines. As previously reported in the literature, in this work we found an increased detection of PCNA in the tumor cells, which showed predictor value only in the univariate analysis of overall cancer survival (22).

Ki-67 is also a proliferation-associated nuclear antigen that recognizes the nuclear antigen during the $G_{1}, S$, and $G_{2} / M$ phases, but not during the $G_{0}$ phase, of the cell cycle $(11,23)$. Equal to PCNA, Ki-67 detection was increased in lung adenocarcinomas and also presented just a univariate correlation with cancer survival. Harpole et al. (11) and Kitamura et al. (23) reported similar findings.

The p53 tumor suppressor gene encodes a nuclear phosphoprotein, which is involved in gene transcription, interrupts the progression of the cell cycle in the $\mathrm{G}_{1}-\mathrm{S}$ phase transition of the cell cycle, and can trigger apoptosis (20-23). Different from the very short half-life of normal wild-type p53 protein, most mutant p53 proteins have a prolonged half-life. p53 wild-type acts as a tumor suppressor protein by binding to the promoter region of the inhibitor p2 $1^{\text {Wafl }}$ gene, preventing the propagation of genetically damaged cells. The arrest in the $G_{1}$ phase allows cells to repair DNA damage; if this fails, then the cells undergo apoptosis. Mutant p53 fails to cause $G_{1}$ arrest, and the cells with DNA damage continue to divide and the accumulating mutations lead to neoplastic transformation. It is interesting that our study showed an increased immunohistochemical detection of p53 protein in adenocarcinomatous cells and presented a significant relationship to cancer overall survival. Several reports in the literature have emphasized this association in lung carcinomatous cells (11, 19-23). Data from our study showed that high indexes of PCNA, 
Ki-67, and p53 were significantly associated with cancer recurrence and death caused by cancer, in the univariate analysis. In the multivariate analysis, p53 index presented a significant association with survival, but PCNA and Ki-67 indexes were eliminated from significance. These findings suggest that PCNA, Ki-67, and p53 indexes may be measuring similar changes and need to be evaluated by multivariate methods.

In summary, on the basis of these results, we conclude that male sex, tumors measuring more than $3 \mathrm{~cm}$, neoplastic involvement of lymph nodes, low proportion of stromal degree, and high immunohistochemical index of p53 may be reliable indicators of recurrence in patients who have operable lung adenocarcinoma, and their overall treatment should be improved by the evaluation of those variables.

\section{REFERENCES}

1. Liotta LA, Rao CN, Barsky SH. Tumor invasion and the extracellular matrix. Lab Invest 1983;49:636-49.

2. Bernfield MR, Banerjee SD, Cohn RH. Dependence of salivary epithelial morphology and branching morphogenesis upon acid mucopolysaccharide-protein (proteoglycan) at the epithelial surface. J Cell Biol 1972;52:674-89.

3. Gospodarowicz D, Greenburg G, Birdwell CR. Determination of cellular shape by the extracellular matrix and its correlation with the control of cellular growth. Cancer Res 1978;38: 4155-71.

4. Grigioni WF, Biagini G, Garbisa S, D’Errico A, Milani M, Mastrorilli $\mathrm{M}$, et al. Immunohistochemical study of basement membrane antigens in bronchioloalveolar carcinoma. Am J Pathol 1987;128:217-24.

5. Liotta LA. Tumor invasion and metastases-Role of the extracellular matrix: Rhoads Memorial Award Lecture. Cancer Res 1986;46:1-7.

6. S申rensen JB, Olsen JE. Prognostic implications of histopathologic subtyping in patients with surgically treated stage I or II adenocarcinoma of the lung. J Thorac Cardiovasc Surg 1989;97:245-51.

7. Tubiana M, Courdi A. Cell proliferation kinetics in human solid tumors: relation to probability of metastatic dissemination and long-term survival. Radiother Oncol 1989;15:118.

8. Mountain CF. A new international staging system for lung cancer. Chest 1986;89(Suppl):225-33.

9. The World Health Organization histological typing of lung tumors. 2nd ed. Am J Clin Pathol 1982;77:123-36.

10. Gundersen HJG, Bendtsen TF, Korbo L, Marcussen N, M $\phi$ ller A, Nielsen K, et al. Some new, simple and efficient stereological methods and their use in pathological research and diagnosis. APMIS 1988;96:379-94.

11. Harpole D Jr, Herndon JE II, Wolfe WG, Iglehart JD, Marks JR. A prognostic model of recurrence and death in stage I non-small lung cancer utilizing presentation, histopathology, and oncoprotein expression. Cancer Res 1995;55:51-6.

12. Shi SR, Key ME, Kalra KL. Antigen retrieval in formalin-fixed, paraffin-embedded tissues: an enhancement method for immunohistochemical staining based on microwave oven heating of tissue sections. J Histochem Cytochem 1991;39: 741-8.

13. Kerns BJM, Jordan PA, Moore MB, Humphrey PA, Berchuck A, Kohler MF, et al. p53 overexpression in formalin-fixed, paraffin-embedded tissue detected by immunohistochemistry. J Histochem Cytochem 1992;40:1047-51.

14. Cox, DR. Regression models and life tables. J R Stat Soc 1972;34:187-200.

15. Charloux A, Rossignol M, Purohit A, Small D, Wolkoven N, Pauli G, et al. International differences in epidemiology of lung adenocarcinoma. Lung Cancer 1997;16:133-43.

16. Naruke T, Goya T, Tsuchya R, Suemasu K. Prognosis and survival in resected lung carcinoma based on the new international staging system. J Thorac Cardiovasc Surg 1988;96: 440-7.

17. Chung CK, Zaino R, Stryker JA, O’Neill M Jr, DeMuth WE Jr. Carcinoma of the lung: evaluation of histological grade and factors influencing prognosis. Ann Thorac Surg 1982;33:599604.

18. Hukill PB, Stern H. Adenocarcinoma of the lung: histological factors affecting prognosis. A study of 38 patients with resection and 5-year survival. Cancer 1962;15:504-14.

19. Kern JA, Filderman AE. Oncogenes and growth factors in human lung cancer. Lung Cancer 1993;14:31-41.

20. Mountain CF. New prognostic factors in lung cancer. Biologic prophets of cancer cell aggression. Chest 1995;108:24654.

21. Salgia R, Skarin AT. Molecular abnormalities in lung cancer. J Clin Oncol 1998;16:1207-17.

22. Ebina M, Steinberg SM, Mulshine JL, Linnoila RI. Relationship of p53 overexpression and up-regulation of proliferating cell nuclear antigen with the clinical course of non-small cell lung cancer. Cancer Res 1994;54:2496-503.

23. Kitamura H, Kameda $Y$, Nakamura N, Nakatani $Y$, Inayama $\mathrm{Y}$, Iida M, et al. Proliferative potential and p53 overexpression in precursor and early stage lesions of bronchioloalveolar lung carcinoma. Am J Pathol 1995;146:876-87.

24. Asamura H, Nakajima T, Mukai K, Shimosato Y. Nuclear DNA content by cytofluorometry of stage I adenocarcinoma of the lung in relation to postoperative recurrence. Chest 1989;96:312-8.

25. Shimosato Y, Hashimoto T, Kodama T, Kameya T, Suzuki A, Nishiwaki Y, et al. Prognostic implications of fibrotic focus (scar) in small peripheral lung cancers. Am J Surg Pathol 1980;4:365-73.

26. Ohori NP, Yousem AS, Griffin J, Stanis K, Stetler-Stevenson WG, Colby TV, et al. Comparison of extracellular matrix antigens in subtypes of bronchioloalveolar carcinoma and conventional pulmonary adenocarcinoma: an immunohistochemical study. Am J Surg Pathol 1992;16:675-86.

27. Watanabe N, Nakajima I, Abe S, Ogura S, Isobe H, Kawakami Y. Staining pattern of type IV collagen and prognosis in early stage adenocarcinoma of the lung. J Clin Pathol 1994;47:613-5.

28. Barsky SH, Huang SJ, Bhuta S. The extracellular matrix of pulmonary scar carcinomas is suggestive of a desmoplastic origin. Am J Pathol 1986;124:412-9.

29. Fontanini G, Vignati S, Bigini D, Mussi A, Lucchi H, Angeletti $\mathrm{CA}$, et al. Epidermal growth factor receptor (EGFr) expression in non-small cell lung carcinomas correlates with metastatic involvement of hilar and mediastinal lymph nodes in the squamous subtype. Eur J Cancer 1995;31A:178-83.

30. Grigioni WF, Garbisa S, D'Errico A, Baccarini P, StetlerStevenson WG, Liotta LA, et al. Evaluation of hepatocellular carcinoma aggressiveness by a panel of extracellular matrix antigens. Am J Pathol 1991;138:647-54.

31. Soini Y, Pääkkö P, Autio-Harmainen H. Genes of laminin B1 chain $\alpha 1$ (IV) chain of type collagen, and 72-kd type IV collagenase are mainly expressed by the stromal cells of lung carcinomas. Am J Pathol 1993;142:1622-30.

32. Madri JA, Carter D. Scar cancers of the lung. Origin and significance. Hum Pathol 1984;15:625-31.

33. Takise A, Kodama T, Shimosato Y, Watanabe S, Suemasu K. Histopathologic prognostic factors in adenocarcinomas of 
the peripheral lung less than $2 \mathrm{~cm}$ in diameter. Cancer 1988;61:2083-8.

34. Lee TK, Horner RD, Silverman JF, Chen YH, Jenny C, Scarantino CW. Morphometric and morphologic evaluations in stage III non-small cell lung cancers. Cancer 1989;63:309-16.

35. Bernardi FC, Antonângelo L, Beyruti R, Takagaki T, Saldiva PHN, Capelozzi VL. A prognostic model of survival in surgically resected squamous cell carcinoma of the lung using clinical, pathologic, and biologic markers. Mod Pathol 1997; 10:992-1000.

36. Gail MH, Eagan RT, Feld R, Ginsberg R, Goodel B, Hill L, et al., The Lung Cancer Study Group. Prognostic factors in patients with resected stage I non-small cell lung cancer. A report from the Lung Cancer Study Group. Cancer 1984;54: 1802-13.

37. Noguchi M, Morikawa M, Kawasaki M, Matsuno Y, Yamada T, Hirohashi S, et al. Small adenocarcinoma of the lung: histologic characteristics and prognosis. Cancer 1995;75: 2844-52.

38. Giatromanolaki A, Koukourakis M, O'Byrne K, Fox S, Whitehouse R, Talbot DC, et al. Prognostic value of angiogenesis in operable non-small cell lung cancer. J Pathol 1996;179:80-8.

\section{Book Review}

\section{Damjanov I, Linder J: Pathology: A Color Atlas, 476 pp, St. Louis, Mosby, 2000 (\$195).}

Following a tradition of excellence established by Professors Sandritter (Germany) and Curran (England), Drs. Damjanov and Linder have given us an outstanding color atlas that combines high-quality photomicrographs (more than 1400) with excellent color photographs of gross specimens. In addition, the textual material is combined with tables and line illustrations that add to the readability. Immunofluorescent stains are included when necessary, and although most of the entities illustrated and discussed are of the more common conditions that one finds in standard textbooks, on occasion a "rare find" is also included, to the delight of the reader.

As a reviewer, it is only fair to mention the (few) negatives that I found, all easily correctable in a future edition. There were several typographical errors: the photomicrographs, Figure 5-4 and 5-5, p. 75, Parvovirus B-19 and Sarcoid, were transposed; $L D$ variant of Hodgkin's disease was called radicular instead of reticular p. 87; on p. 210, the dysplastic kidney was erroneously referred to as "definitive"; and the diagram on p. 409, labeled "Major tumors of the CNS by age and location," showed sites of CNS infections rather than tumors. In addition, as points of disagreement, nerve sheath myxomas and neurothekeomas are not considered synonymous by most authors, and the pigmentation seen in uveal melanomas is not necessarily a prognostic indicator of the tumors' behavior.

Despite these negatives, we must be grateful to Drs. Damjanov and Linder for providing us with this wonderfully illustrated atlas (and text). One can easily appreciate what a painstaking effort it was to compile so many high-quality gross specimens that clearly show the lesion under discussion and integrate them with the textual and photomicrographic material. This is a wonderful addition to our literature, and I enthusiastically recommend that a copy of this book be found in every pathologist's library.

\author{
Larry I. Giltman \\ Emory University School of Medicine \\ Veterans Affairs Medical Center \\ Atlanta, Georgia
}

